\title{
Fertility preservation for young adults, adolescents, and children with cancer
}

\author{
Kenny A. Rodriguez-Wallberg ${ }^{\mathrm{a}, \mathrm{b}}$ (D), Amandine Anastacio ${ }^{\mathrm{a}}$, Emelie Vonheim ${ }^{\mathrm{b}}$, Sandra Deen ${ }^{\mathrm{b}}$, Johan Malmros ${ }^{\mathrm{c}}$ \\ and Birgit Borgström ${ }^{d}$ \\ ${ }^{a}$ Department of Oncology-Pathology, Karolinska Institutet, Stockholm, Sweden; ${ }^{b}$ Division of Gynecology and Reproduction, Department of \\ Reproductive Medicine, Karolinska University Hospital, Stockholm, Sweden; 'Department of Pediatric Oncology, Karolinska University \\ Hospital, Stockholm, Sweden; ${ }^{d}$ Department of Pediatric Endocrinology, Karolinska University Hospital, Stockholm, Sweden
}

\begin{abstract}
Options for fertility preservation (FP) through cryopreservation methods are currently available for young adults, adolescents, and children. Guidelines for FP have been provided by international clinical societies, and emergency procedures aimed at FP have been implemented into clinical practice worldwide. In this article, we review the current data on clinical standards of emergency FP in patients who are facing gonadotoxic effects of cancer treatment, and we also describe the methods that are still under development, usually denoted as experimental. In Sweden, programmes for FP have been established at large university hospitals, thus covering the whole country. The Swedish publicly financed health care covers both assisted reproduction for treatment of infertility and the cryopreservation of gametes or gonadal tissue when there is a medical indication, such as the risk to become infertile due to oncologic treatment; hence the access to FP is ensured for the whole population. At our centre at Karolinska University Hospital in Stockholm, methods for FP have been offered since 1988. In this article, we also review the oncologic indications for FP in our patient cohort of $>3000$ individuals during the period 1988-2018.
\end{abstract}

\section{ARTICLE HISTORY}

Received 28 January 2020

Revised 17 February 2020

Accepted 27 February 2020

\section{KEYWORDS}

Cancer survivorship; cryopreservation; fertility preservation; gonadotoxicity; premature gonadal failure; young adults and children

\section{Introduction}

Fertility preservation (FP) is a modern clinical field that combines medical and technical developments in reproductive medicine and their application to patients with serious diseases, such as cancer, or with benign clinical conditions associated with a premature onset of gonadal insufficiency (1). International guidelines have stated that timely information on methods for FP should be provided to all patients of young age when planning gonadotoxic treatments, as well as to the parents or guardians of children in such clinical situation $(2,3)$. Cryopreservation of reproductive cells and tissues is a fundamental tool in the development of clinical programmes for FP (4).

\section{Development of clinically established and experimental methods for FP: first sperm, thereafter embryos, and then oocytes and gonadal tissue}

Historically, efficacious methods for sperm cryopreservation were achieved first, already in the 1950s, facilitated by the usually large number of spermatozoa obtained per sample and the possibility to use them for research (5). Thereafter, the development of treatments using assisted reproductive technologies (ART), resulting in multiple embryos produced per treatment, also required a further development of methods to cryopreserve supernumerary embryos for later use. These were reported successful for the first time already in 1983 (6).

However, for cryopreservation of oocytes, the advances have been slow. This has been due to the technical difficulties that arise as a consequence of the large cell size and water content of the oocytes, which makes the cells more prone to damage during cryopreservation and thawing (7). Research in development of efficient methods to cryopreserve oocytes advanced also slowly due to their scarcity. Although the first report of successful vitrification appeared in 1997 (8), the clinical validation of cryopreservation of oocytes by vitrification has only recently been achieved $(9,10)$, and the method became clinically established and recognized by the large international reproductive societies in $2013(1,4)$.

In addition to these well-established methods for FP, today clinically implemented at most fertility centres worldwide practicing ART, additional FP methods have been developed through years of experimentation. Ovarian tissue cryopreservation for later re-transplantation in humans has been developed through extensive and focussed translational research during the 1990s (11-13). Several cryopreservation protocols have been validated, and large programmes of FP have reported their experiences of cryopreservation of 
ovarian tissue for FP of adult women, adolescents, and prepubertal girls (14-22). In December 2019, the Practice Committee of the American Society of Reproductive Medicine stated that ovarian tissue cryopreservation for FP should no more be considered as experimental (23).

For prepubertal boys, methods for cryopreservation of testicular tissue have also been developed and proposed as a method for FP aiming at the preservation of spermatogonia (24-30). However, the absence of mature sperm in the prepubertal testis is recognized as one of the main difficulties, hence the need of further developments, such as the investigation of tissue transplantation and also the development of in vitro culture systems aiming at obtaining fully viable mature gametes for possible fertility treatment in the future (31).

Although the subject of FP for children may be difficult to approach and it might also be considered ethically debateable, survivors of cancer in childhood have ranked it as an important quality-of-life issue. International guidelines supporting promotion of FP for children have thus been provided $(1,2,23,27,32,33)$. In Sweden, a multidisciplinary group including all university hospitals has also provided national guidelines to ensure that healthcare providers become familiar with the available methods for FP and to facilitate access to FP counselling for children and teenagers with cancer (34). At Karolinska University Hospital in Stockholm, methods for FP have been offered since 1988. The patient cohort currently includes $>3000$ individuals, adults and children, and the cohort is prospectively followed under studies approved by the Regional Ethics Committee and performed according to the principles of the Declaration of Helsinki.

\section{Why oncologic treatment is an indication for undergoing FP}

The Swedish cancer statistics indicate that one in three people will receive a cancer diagnosis during their lifetime, and the number of cancer cases is increasing every year (35). Although most cancers occur in aged people, cancer can also present in young adults and children. Cancer registration data in Europe and in the USA have shown increasing rates of survival, above $80 \%$, in particular for several diseases and for the youngest patients, such as those presenting with cancer during childhood or young adulthood (35). Survivorship issues have thus come to the frontline as quality of survival is highly relevant for the patients (36-38).

In most cancers, the treatment strategies using chemotherapy, radiotherapy, or surgery are likely to cause permanent infertility (Figure 1) (32). Chemo- and radiotherapeutic gonadotoxic effects are dose-dependent, and some of those effects have been well characterized regarding the protocols used. Table 1 summarizes radiation doses and radiotherapy protocols that may impact on ovarian and testicular function (33). Irradiation of the uterus may also negatively affect the chances to conceive and increase obstetric risks.

As regards chemotherapeutic agents, those are usually given as part of a combination regimen. This fact has contributed to the difficulty in achieving a precise gonadotoxic quantification of individual drugs. Table 2 shows a list of chemotherapeutic agents according to the currently known gonadotoxic impact in females and males.

In female patients, gonadotoxicity is particularly dependent on age, because the number of primordial follicles that constitute the ovarian pool is non-renewable, and it diminishes with age. Older women would thus have a higher risk of developing permanent infertility due to follicle depletion, when compared with younger women undergoing a similar treatment. In men, younger age or a prepubertal status does not provide protection against the damage induced by chemotherapeutic drugs (39).

\section{Banking of frozen sperm}

Sperm cryopreservation is a standard of care for adolescents and young adults facing gonadotoxic treatment such as the one required for treatment of cancer. It is usually feasible from around 12 years of age, when spermarche usually has been achieved and the testis volume has reached $8 \mathrm{ml}(40,41)$.

Most studies in the field of FP advocate that all patients of reproductive age should be advised to bank frozen sperm prior to initiating gonadotoxic therapy (42).

In cases of ejaculation failure, search for spermatozoa in a urine sample could be proposed. Testicular sperm extraction can also be offered, aiming to retrieve spermatozoa in young men and adolescents (33). Other methods described for retrieval of spermatozoa in adolescents include penile vibratory stimulation and electro-ejaculation.

In Sweden, the costs for sperm cryopreservation are covered by the tax-funded healthcare system up to a male age of 55 years. In other countries, patients may need to cover the costs of the procedures and a fee for maintaining the frozen samples. The average cost in the United States for banking three samples varies from $\$ 25$ to $\$ 35$ per month. Economic barriers have been discussed in previous studies as a limitation to patients' access to FP $(2,3)$.

\section{Oncologic indications for sperm cryopreservation in the Karolinska cohort}

At the Reproductive Medicine Clinic of Karolinska University Hospital sperm cryopreservation aiming at FP has been offered since 1988. Referrals of patients with oncologic indications can be accepted without any delay, and the patients may approach the fertility laboratory also during weekends. Between 1 January 1998 and 31 December 2018, 1749 male patients have been referred for sperm cryopreservation to our centre. Of those, 356 presented with benign diseases. Figure 2 summarizes the data of 1393 patients referred for oncologic indications that had sperm cryopreserved at our centre during that period. The most frequent oncologic diagnoses in young men and teenagers include testicular cancer and haematologic malignancies. Over $80 \%$ of patients had two to three samples banked (range 1-7). Young adolescents have been able to provide sperm samples for 


\section{If the treatment includes: The following options should be considered:}

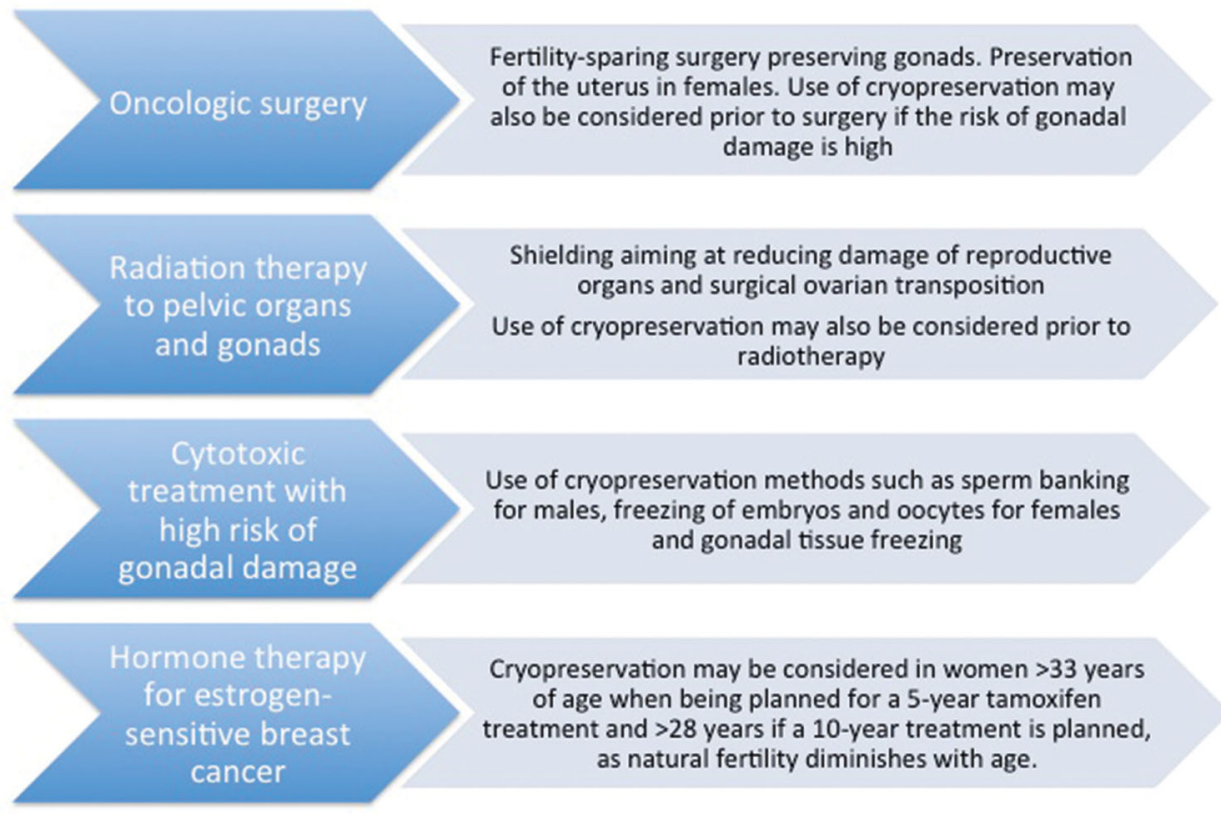

Figure 1. Fertility preservation (FP) strategies according to modalities of cancer treatment. Reprinted, with permission from: Rodriguez-Wallberg and Oktay (32). Originally published by and used with permission from Dove Medical Press Limited.

Table 1. Radiotherapy protocols with high or intermediate impact on ovarian and testicular function. Modified from Rodriguez-Wallberg and Oktay (33).

\section{Radiotherapy protocols and their risk of prolonged azoospermia in men or amenorrhoea in women}

High risk

Total body irradiation (TBI) for bone marrow transplant/stem cell transplant

Testicular radiation dose $>2.5 \mathrm{~Gy}$ in adult men

Testicular radiation dose $\geq 6 \mathrm{~Gy}$ in prepubertal boys

Pelvic or whole-abdominal radiation dose $>6 \mathrm{~Gy}$ in adult women

Pelvic or whole-abdominal radiation dose $\geq 10 \mathrm{~Gy}$ in postpubertal girls

Pelvic radiation or whole-abdominal dose $>15 \mathrm{~Gy}$ in prepubertal girls

Intermediate risk

Testicular radiation dose $1-6 \mathrm{~Gy}$ from scattered pelvic or abdominal radiation

Pelvic or whole-abdominal radiation dose $5-10 \mathrm{~Gy}$ in postpubertal girls

Pelvic or whole-abdominal radiation dose $10-15 \mathrm{~Gy}$ in prepubertal girls

Craniospinal radiotherapy dose $\geq 25$ Gy $14^{\mathrm{a}}$

${ }^{\mathrm{a} C r a n i a l}$ irradiation for the treatment of brain tumours may induce infertility in both female and male patients by disruption of the hypothalamic-pituitary-gonadal axis and disturbance of gonadotropin secretion.

cryopreservation from the age of 14 years. The mean age at sperm banking was 31 years (range 14-61).

Cryopreservation of embryos, oocytes, and ovarian tissue Cryopreservation of embryos, oocytes, and ovarian tissue are methods clinically established for female FP. For embryo and oocyte cryopreservation, hormonal stimulation with gonadotropins is needed, to induce multiple follicle recruitment aiming at obtaining more than one mature oocyte per treatment cycle.

Stimulation protocols using a GnRH antagonist are currently preferred for $\mathrm{FP}$, as these minimise the time required for ovarian stimulation. The protocols can also be applied with random initiation (random start), that is, regardless of the woman's cycle day. In general, the delay to egg retrieval is shortened to about 2 weeks in most cases $(22,43-46)$.

Improvements of stimulation protocols for women with breast cancer undergoing FP aiming at an increase of their safety have been proposed, in particular with co- administration of letrozole alongside gonadotropins, together with a GnRHa maturation trigger (47). This specific protocol has been demonstrated to reduce the expected several fold increase in systemic oestrogen levels during conventional hormonal stimulation. Furthermore, it achieves low systemic oestrogen levels, similar to those found in a normal menstrual cycle, even though multiple follicles develop responding to the exogenous gonadotropins (47). The number of oocytes obtained in cycles with letrozole is similar to that obtained using standard protocols, and their maturity rate does not seem to differ from those obtained with conventional gonadotropin stimulation protocols $(46,47)$. Co-administration of tamoxifen has been also proposed for FP of women with breast cancer. However, protocols with letrozole have demonstrated higher efficacy than those with tamoxifen in a prospective controlled study (48).

In Sweden, protocols with co-administration of letrozole for FP of women with breast cancer have been implemented at Karolinska University Hospital since 2009 and thereafter at the remaining large university hospitals (46). A recent large 
Table 2. Chemotherapy agents according to their gonadotoxic impact in females (amenorrhoea) and males (azoospermia).

\begin{tabular}{l} 
Chemotherapy agents \\
\hline High risk \\
Cyclophosphamide \\
Ifosfamide \\
Melphalan \\
Busulfan \\
Nitrogen mustard \\
Procarbazine \\
Chlorambucil \\
Intermediate risk \\
Cisplatin with low cumulative dose \\
Carboplatin with low cumulative dose \\
Adriamycin \\
Low risk \\
Treatment protocols for Hodgkin's lymphoma without alkylating agents \\
Bleomycin \\
Actinomycin D \\
Vincristine \\
Methotrexate \\
5-Fluorouracil \\
Radioiodine treatment for thyroid cancer \\
Unknown risk \\
Paclitaxel and docetaxel for treatment of breast cancer \\
Irinotecan \\
Trastuzumab \\
Imatinib \\
Erlotinib \\
Bevacizumab \\
\hline
\end{tabular}

prospective study including all Swedish centres reporting on women with breast cancer undergoing hormonal stimulation for FP indicates that the proposed improvements to antagonist protocols for emergency FP including random-start and co-administration of letrozole are efficacious, as regards treatment outcomes in terms of oocytes and embryos obtained and cryopreserved (46).

The safety of hormonal stimulation in women with breast cancer aiming at FP has also been investigated in several studies (46,49-51). A systematic review published in 2017 indicated no increased risks (52). A recent population-based study with matched cohort design including 188 women with breast cancer that underwent FP from 1999 to 2013 in Sweden indicated no increased risk of cancer recurrence, when compared with 378 age-matched controls (53).

It is recommended that standardized counselling on FP should be provided early in the process of cancer diagnosis and treatment, to allow the patients to make decisions as regards safeguarding of their future fertility potential. For women with a male partner and with enough time to undergo hormonal stimulation, it has been established to present the option to cryopreserve embryos in the first place, mainly due to the lack of confidence in methods for cryopreservation of unfertilised oocytes during many years, as the method of oocyte vitrification was only accepted as clinically developed in 2013 (1). A large prospective study in Sweden has identified recent changes in trends regarding patient decisions after standardized counselling for FP (22). In the Swedish cohort, an increasing number of women in committed relationships have chosen to cryopreserve unfertilized oocytes, which is important as it provides autonomy to the women (22). In many countries, law constraints currently include the requirement that the two partners are together at the time of the use of the cryopreserved embryos. Indeed, this may be detrimental to women having cryopreserved embryos if the couples split later on (22).

In cases when hormonal stimulation or transvaginal oocyte retrieval are not suitable, or when there is not enough time, the only method available for FP is cryopreservation of ovarian tissue. This is also the only method that can be offered to prepubertal girls $(2,3,22,23,32,33)$. Several clinical programmes of FP have reported ovarian tissue cryopreservation for adult women and girls worldwide (14-22). In Scandinavia, programmes of FP include ovarian tissue cryopreservation at nearly all centres (19).

\section{Oncologic diagnoses in females attempting FP in the Karolinska cohort}

A detailed analysis of the cohort of women and girls that have undergone procedures for FP due to oncologic conditions at Karolinska University Hospital has been recently reported (22). In total 1254 females had been referred to our centre between 1 January 1998 and 31 December 2018. In 402 cases the indication was a benign condition (22). Figure 3 illustrates the most frequent diagnosis in the Karolinska cohort, which included 852 women and girls with cancer who underwent procedures for FP during the period 1998-2018, with a mean age of 27.8 years (range 1-43) (22).

\section{Utilisation rates of sperm, oocytes, and embryos and efficacy of FP in the long term}

In general, follow-up studies indicate a low utilisation rate of embryos, oocytes, sperm, and gonadal tissue aimed at FP. The most frequent causes of not proceeding to use reproductive cells or tissues is the current lack of a partner, or the oncological recommendation to postpone pregnancy until a long-enough follow-up time after cancer treatment (22).

Regarding frozen banked sperm, usage rates have been reported to be less than $10 \%$ (54). In previous large studies, the utilization rate reported has been as low as $7 \%(55,56)$, and large data have been analysed in a systematic review in 2016 (57). These low numbers have brought up the discussion of the cost-effectiveness of sperm banking. Even though usage rates are low, it has been argued that there might be other benefits of banking sperm, such as the psychological and emotional benefit of giving the patient hope in a long-term survival.

For women, comparable studies of large sample size are notoriously scarce. A previous retrospective study of women that returned for thawing their oocytes or embryos (58) reported an embryo implantation rate of $27 \%$ and live birth rate (LBR) of $44 \%$ per embryo transfer (58). Most studies have been retrospective and report on the outcome of healthy women undergoing elective oocyte freezing. In a Spanish cohort, a number of 8-10 mature oocytes was found to be associated with a reasonable chance of success, with a mean of 10 oocytes resulting in $60.5 \%$ live birth rate (LBR) in the women that returned. Of note, the LBR was reduced when the women were older than 36 years (59), and several studies have confirmed an association of older age with poorer outcome as regards retrieved oocyte yields (22,58-60). In the 


\section{Type of cancer}

\begin{tabular}{|l|c|}
\hline INDICATION & N \\
\hline Testicular cancer & 682 \\
\hline Lymphoma & 258 \\
\hline Leukemia, MDS & 136 \\
\hline CNS malignancy & 53 \\
\hline Colo-rectal cancer & 47 \\
\hline Malignant, other & 144 \\
\hline Urogenital cancer & 73 \\
\hline TOTAL & 1393 \\
\hline
\end{tabular}
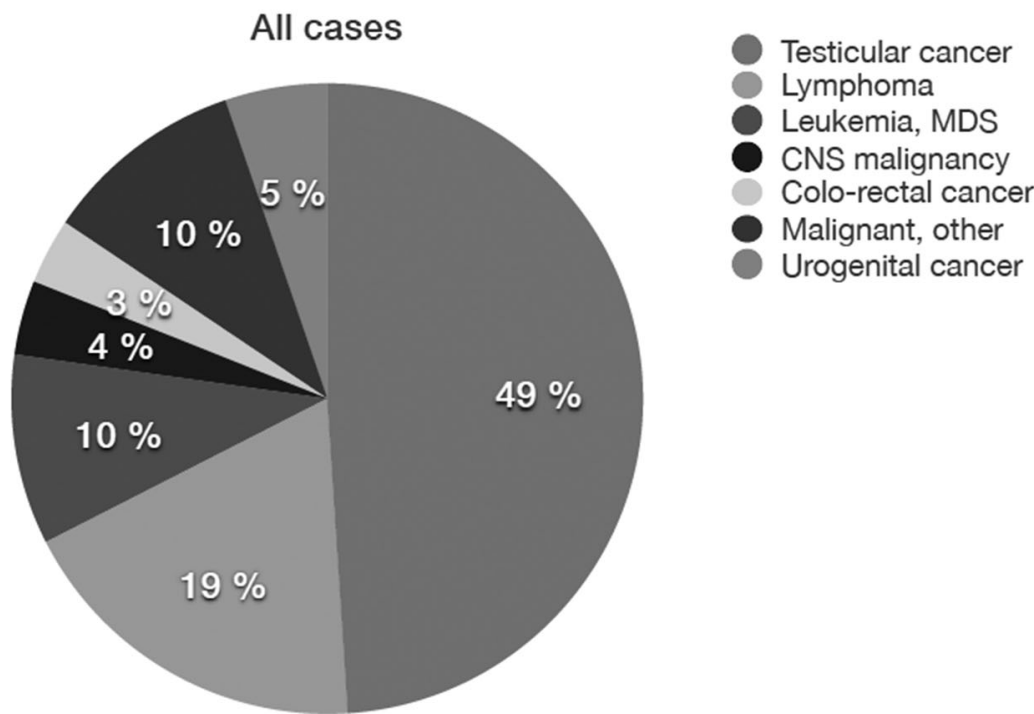

Figure 2. Oncologic indications for sperm banking in a cohort of adolescents and young adults at Karolinska University Hospital 1988-2018 ( $n=1393$ ). MDS: Myelodysplastic Syndrome.

women that return to attempt pregnancy following $\mathrm{FP}$, a malignant indication of FP has been associated with a reduced $L B R$, when compared with that of women that have undergone FP for benign indications $(22,60)$. In the Karolinska cohort, the rate of utilization of embryos, oocytes, or ovarian tissue in women of childbearing age who had a follow-up of at least 1 year after FP were $29 \%, 8 \%$, and 5\%, respectively, with pregnancy rates of $66 \%, 54 \%$, and $25 \%$, and LBR of $54 \%$, $46 \%$, and $7 \%$, respectively (22).

The efficacy of re-transplantation of ovarian tissue has been compared with the use of vitrified oocytes in a previous Spanish study of 44 women that underwent re-transplantation of ovarian tissue versus 49 women who thawed vitrified oocytes (18). The researchers found a trend towards higher pregnancy and LBR following use of thawed oocytes (RR 1.31, 95\% Cl 0.90-1.92; RR 1.39, 95\% Cl 0.95-2.03, respectively) (18), although it did not reach statistical significance.

\section{Future developments}

Gonadal tissue re-transplantation is the currently feasible way to regain fertility following cancer treatment in women that have cryopreserved ovarian tissue and developed ovarian insufficiency. Since the first report of a live birth following ovarian tissue re-transplantation in 2004 (61), an increasing number of transplantation procedures have been reported by large FP programmes, and the number of live births following these procedures is increasing (14-22,62-65). However, re-transplantation may be precluded in cases where there is a high risk of reintroducing malignant cells. Maturing gametes in vitro will be a probable option for these patients in the future. The methods are currently functioning in animal models, and experiments using human ovarian tissue donated for research have also reported success in follicle growth and maturation (65-68). Nevertheless, there are not yet reported human studies of fertilization of in vitro grown oocytes and subsequent embryo development.

Because research is ongoing and advances are expected, even patients with malignancy compromising the gonads could be offered FP through gonadal tissue cryopreservation, with the aim to wait for the development of in vitro methods that could result in a fertility treatment in the future. This is also the case of prepubertal 
Type of cancer

\begin{tabular}{|l|c|}
\hline INDICATION & N \\
\hline Breast cancer & 390 \\
\hline Gynecological cancer & 123 \\
\hline Lymphoma & 144 \\
\hline Sarcoma & 37 \\
\hline Leukemia and MDS & 32 \\
\hline Colo-rectal cancer & 23 \\
\hline CNS & 8 \\
\hline Other & 38 \\
\hline Previous chemotherapy & 57 \\
\hline TOTAL & 852 \\
\hline
\end{tabular}

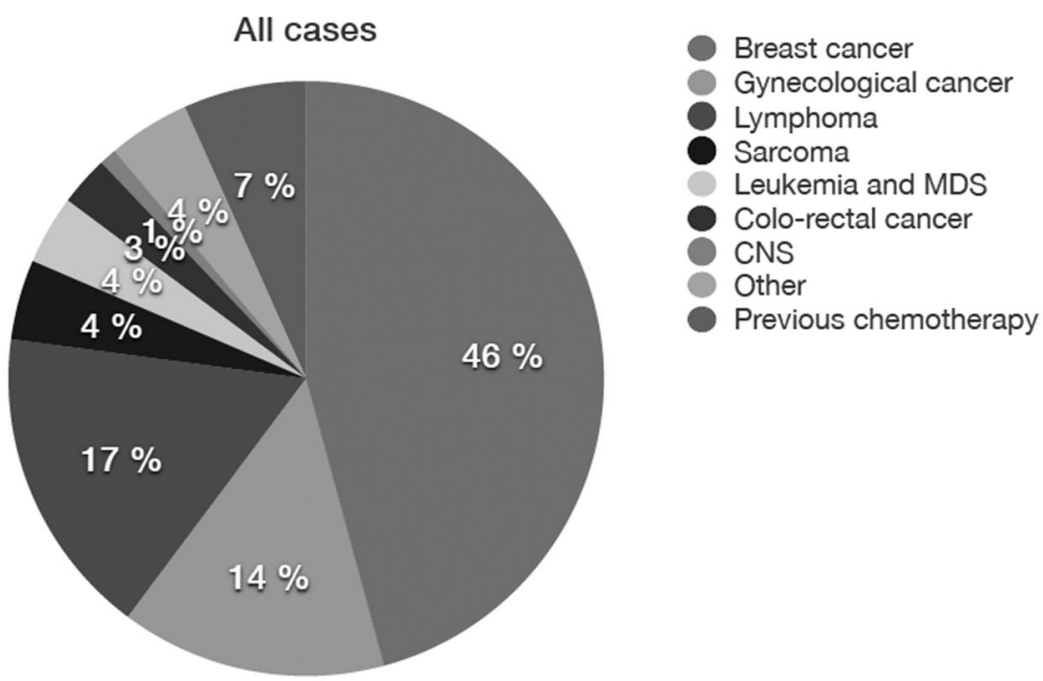

Figure 3. Oncologic indications for fertility preservation (FP) through egg/embryo or ovarian tissue freezing in a cohort of young adult females and girls at Karolinska University Hospital 1998-2018 $(n=852)$. MDS: Myelodysplastic Syndrome.

boys, for whom there are not yet methods developed. There is international consensus that FP through gonadal tissue cryopreservation could be offered only within Ethical Review Board-approved research protocols $(1,2,23,32-34,66,69)$. For prepubertal males for whom only spermatogonia can be preserved but mature sperm are not present, there is also a need of further development of methods to obtain fully mature gametes in vitro or through re-transplantation (23-30,68-71).

\section{Acknowledgements}

The personnel at the Departments of Reproductive Medicine, Oncology, Pediatric Endocrinology and Pediadric Oncology of Karolinska University Hospital are gratefully acknowledged.

\section{Disclosure statement}

No potential conflict of interest was reported by the author(s).

\section{Funding}

The Swedish Cancer Society, The Swedish Childhood Cancer Fund, Radiumhemmets Forskningsfonder, Stockholm County Council, and Karolinska Institutet.

\section{Notes on contributors}

Kenny A. Rodriguez-Wallberg, $\mathrm{MD}, \mathrm{PhD}$, Associate professor and Associate senior lecturer at the Department of Oncology-Pathology of Karolinska Institutet; Senior consultant at the Department of Reproductive Medicine, Karolinska University Hospital.

Amandine Anastacio, PhD, Postdoctoral Fellow at the Department of Oncology-Pathology of Karolinska Institutet, Stockholm, Sweden.

Emelie Vonheim, MD, Karolinska Institutet and University Hospital.

Sandra Deen, MD, Karolinska Institutet and University Hospital.

Johan Malmros, MD, PhD, Senior consultant at the Department of Paediatric Oncology, Karolinska University Hospital.

Birgit Borgström, MD, PhD, Senior consultant at the Department of Paediatric Endocrinology, Karolinska University Hospital. 


\section{ORCID}

Kenny A. Rodriguez-Wallberg (iD http://orcid.org/0000-0003-4378-6181

\section{References}

1. Practice Committee of American Society for Reproductive Medicine. Fertility preservation in patients undergoing gonadotoxic therapy or gonadectomy: a committee opinion. Fertil Steril 2013;100:1214-23.

2. Oktay K, Harvey BE, Partridge AH, Quinn GP, Reinecke J, Taylor H, et al. Fertility preservation in patients with cancer: ASCO clinical practice guideline update. JCO. 2018;36:1994-2001. doi:10.1200/ JCO.2018.78.1914

3. Yasmin E, Balachandren N, Davies MC, Jones GL, Lane S, Mathur R, et al. Fertility preservation for medical reasons in girls and women: British fertility society policy and practice guideline. Hum Fertil (Camb). 2018;21:3-26. doi:10.1080/14647273.2017.1422297

4. Rodriguez-Wallberg KA, Waterstone M, Anastácio A. Ice age: cryopreservation in assisted reproduction - an update. Reprod Biol. 2019;19:119-26. doi:10.1016/j.repbio.2019.04.002

5. Mocé E, Fajardo AJ, Graham JK. Human sperm cryopreservation. Eur Med J. 2016;1:86-91.

6. Trounson A, Mohr L. Human pregnancy following cryopreservation, thawing and transfer of an eight-cell embryo. Nature 1983; 305:707-9. doi:10.1038/305707a0

7. lussig B, Maggiulli R, Fabozzi G, Bertelle S, Vaiarelli A, Cimadomo $D$, et al. A brief history of oocyte cryopreservation: arguments and facts. Acta Obstet Gynecol Scand. 2019;98:550-8. doi:10.1111/ aogs.13569

8. Porcu E, Fabbri R, Seracchioli R, Ciotti PM, Magrini O, Flamigni C. Birth of a healthy female after intracytoplasmic sperm injection of cryopreserved human oocytes. Fertil Steril. 1997;68:724-6. doi:10. 1016/S0015-0282(97)00268-9

9. Glujovsky D, Riestra B, Sueldo C, Fiszbajn G, Repping S, Nodar F, et al. Vitrification versus slow freezing for women undergoing oocyte cryopreservation. Cochrane Database Syst Rev. 2014;5: CD010047.

10. Cobo A, Meseguer M, Remohi J, Pellicer A. Use of cryo-banked oocytes in an ovum donation programme: a prospective, randomized, controlled, clinical trial. Hum Reprod. 2010;25:2239-46. doi: 10.1093/humrep/deq146

11. Gosden RG, Baird DT, Wade JC, Webb R. Restoration of fertility to oophorectomized sheep by ovarian autografts stored at -196 degrees C. Hum Reprod. 1994;9:597-603. doi:10.1093/oxfordjournals.humrep.a138556

12. Baird DT, Webb R, Campbell BK, Harkness LM, Gosden RG. Longterm ovarian function in sheep after ovariectomy and transplantation of autografts stored at -196 C. Endocrinology. 1999;140: 462-71. doi:10.1210/endo.140.1.6453

13. Anderson RA, Baird DT. The development of ovarian tissue cryopreservation in Edinburgh: translation from a rodent model through validation in a large mammal and then into clinical practice. Acta Obstet Gynecol Scand. 2019;98:545-9. doi:10.1111/aogs. 13560

14. Schmidt KL, Andersen CY, Loft A, Byskov AG, Ernst E, Andersen AN. Follow-up of ovarian function post-chemotherapy following ovarian cryopreservation and transplantation. Hum Reprod. 2005; 20:3539-46. doi:10.1093/humrep/dei250

15. Lawrenz B, Jauckus J, Kupka MS, Strowitzki T, von Wolff $M$. Fertility preservation in $>1,000$ patients: patient's characteristics, spectrum, efficacy and risks of applied preservation techniques. Arch Gynecol Obstet. 2011;283:651-6. doi:10.1007/s00404-0101772-y

16. Dolmans MM, Jadoul P, Gilliaux S, Amorim CA, Luyckx V, Squifflet $\mathrm{J}$, et al. A review of 15 years of ovarian tissue bank activities. J Assist Reprod Genet. 2013;30:305-14. doi:10.1007/s10815-0139952-x
17. Imbert R, Moffa F, Tsepelidis S, Simon P, Delbaere A, Devreker F, et al. Safety and usefulness of cryopreservation of ovarian tissue to preserve fertility: a 12-year retrospective analysis. Hum Reprod. 2014;29:1931-40. doi:10.1093/humrep/deu158

18. Diaz-Garcia C, Domingo J, Garcia-Velasco JA, Herraiz S, Mirabet V Iniesta I, et al. Oocyte vitrification versus ovarian cortex transplantation in fertility preservation for adult women undergoing gonadotoxic treatments: a prospective cohort study. Fertil Steril. 2018; 109:478-85.e2. doi:10.1016/j.fertnstert.2017.11.018

19. Rodriguez-Wallberg KA, Tanbo T, Tinkanen $H$, Thurin-Kjellberg A, Nedstrand $\mathrm{E}$, Kitlinski $\mathrm{ML}$, et al. Ovarian tissue cryopreservation and transplantation among alternatives for fertility preservation in the Nordic countries - compilation of 20 years of multicenter experience. Acta Obstet Gynecol Scand. 2016;95:1015-26. doi:10. 1111/aogs.12934

20. Gellert SE, Pors SE, Kristensen SG, Bay-Bjørn AM, Ernst E, Yding Andersen C. Transplantation of frozen-thawed ovarian tissue: an update on worldwide activity published in peer-reviewed papers and on the Danish cohort. J Assist Reprod Genet. 2018;35:561-70. doi:10.1007/s10815-018-1144-2

21. Poirot C, Brugieres L, Yakouben K, Prades-Borio M, Marzouk F, de Lambert $G$, et al. Ovarian tissue cryopreservation for fertility preservation in $\mathbf{4 1 8}$ girls and adolescents up to 15 years of age facing highly gonadotoxic treatment. Twenty years of experience at a single center. Acta Obstet Gynecol Scand. 2019;98:630-7. doi:10. 1111/aogs.13616

22. Rodriguez-Wallberg KA, Marklund A, Lundberg F, Wikander I, Milenkovic $M$, Anastacio $A$, et al. A prospective study of women and girls undergoing fertility preservation due to oncologic and non-oncologic indications in Sweden-Trends in patients' choices and benefit of the chosen methods after long-term follow up. Acta Obstet Gynecol Scand. 2019;98:604-15. doi:10.1111/aogs. 13559

23. Practice Committee of the American Society of Reproductive Medicine. Fertility preservation in patients undergoing gonadotoxic therapy or gonadectomy: a committee opinion. Fertil Steril 2019;112:1022-31.

24. Ginsberg JP, Carlson CA, Lin K, Hobbie WL, Wigo E, Wu X, et al. An experimental protocol for fertility preservation in prepubertal boys recently diagnosed with cancer: a report of acceptability and safety. Hum Reprod. 2010;25:37-41. doi:10.1093/humrep/dep371

25. Wyns C, Curaba M, Petit S, Vanabelle B, Laurent P, Wese JF, et al. Management of fertility preservation in prepubertal patients: 5 years' experience at the Catholic University of Louvain. Hum Reprod. 2011;26:737-47. doi:10.1093/humrep/deq387

26. Babayev SN, Arslan E, Kogan S, Moy F, Oktay K. Evaluation of ovarian and testicular tissue cryopreservation in children undergoing gonadotoxic therapies. J Assist Reprod Genet. 2013;30:3-9. doi:10. 1007/s10815-012-9909-5

27. Picton HM, Wyns C, Anderson RA, Goossens E, Jahnukainen K Kliesch $\mathrm{S}$, et al. A European perspective on testicular tissue cryopreservation for fertility preservation in prepubertal and adolescent boys. Hum Reprod. 2015;30:2463-75. doi:10.1093/humrep/ dev190

28. Carlson CA, Kolon TF, Mattei P, Hobbie W, Gracia CR, Ogle S, et al Developing a hospital-wide fertility preservation service for pediatric and young adult patients. J Adolesc Health. 2017;61:571-6. doi: 10.1016/j.jadohealth.2017.07.008

29. Stukenborg JB, Alves-Lopes JP, Kurek M, Albalushi $H$, Reda $A$, Keros $V$, et al. Spermatogonial quantity in human prepubertal testicular tissue collected for fertility preservation prior to potentially sterilizing therapy. Hum Reprod. 2018;33:1677-83. doi:10.1093/ humrep/dey 240

30. Valli-Pulaski H, Peters KA, Gassei K, Steimer SR, Sukhwani M, Hermann BP, et al. Testicular tissue cryopreservation: 8 years of experience from a coordinated network of academic centers. Hum Reprod. 2019;434:966-77. doi:10.1093/humrep/dez043

31. Ntemou E, Kadam P, Van Saen D, Wistuba J, Mitchell RT, Schlatt S, et al. Complete spermatogenesis in intratesticular testis tissue 
xenotransplants from immature non-human primate. Hum Reprod. 2019;34:403-13. doi:10.1093/humrep/dey373

32. Rodriguez-Wallberg KA, Oktay K. Fertility preservation during cancer treatment: clinical guidelines. Cancer Manag Res. 2014;6: 105-17. doi:10.2147/CMAR.S32380

33. Rodriguez-Wallberg KA, Oktay K. Fertility preservation medicine: options for young adults and children with cancer. J Pediatr Hematol Oncol. 2010;32:390-6. doi:10.1097/MPH. Ob013e3181dce339

34. Rodriguez-Wallberg KA, Borgström B, Petersen C, Thurin-Kjellberg A, Mörse $H$, Giwercman A. National guidelines and multilingual age-adapted patient brochures and videos as decision aids for fertility preservation for children and teenagers with cancer - a multidisciplinary effort to improve children's information and access to fertility preservation in Sweden. Acta Obstet Gynecol Scand. 2019;98:679-80. doi:10.1111/aogs.13588

35. Socialstyrelsen. Cancer i siffror. Populärvetenskapliga fakta om cancer. 2018. Available at: https://static-files.cancerfonden.se/ Cancer\%20i\%20siffror\%202018_laddaner.pdf

36. Schover LR, Rybicki LA, Martin BA, Bringelsen KA. Having children after cancer. A pilot survey of survivors' attitudes and experiences. Cancer 1999;86:697-709. 0142(19990815)86:4<697::AID-CNCR20>3.0.CO;2-J

37. Duffy C, Allen S. Medical and psychosocial aspects of fertility after cancer. Cancer J. 2009;15:27-33. doi:10.1097/PPO. ob013e3181976602

38. Rosen A, Rodriguez-Wallberg KA, Rosenzweig L. Psychosocial distress in young cancer survivors. Semin Oncol Nurs. 2009;25: 268-77. doi:10.1016/j.soncn.2009.08.004

39. Pacey AA. Fertility issues in survivors from adolescent cancers. Cancer Treat Rev. 2007;33:646-55. doi:10.1016/j.ctrv.2007.02.001

40. Nielsen $C T$, Skakkebaek NE, Richardson DW, Darling JAB, Hunter $W M$, Jørgensen $M$, et al. Onset of the release of spermatozoa (spermarche) in boys in relation to age, testicular growth, pubic hair, and height. J Clin Endocrinol Metab. 1986;62:532-5. doi:10. 1210/jcem-62-3-532

41. Ji CY, Ohsawa S. Onset of the release of spermatozoa (spermarche) in Chinese male youth. Am J Hum Biol. 2000;12:577-87. doi:10.1002/1520-6300(200009/10)12:5<577::AID-AJHB1 > 3.0.CO;2-

42. Dohle GR. Male infertility in cancer patients: review of the literature. Int Jour Urol. 2010;17:327-31. doi:10.1111/j.1442-2042.2010. 02484.x

43. von Wolff M, Thaler CJ, Frambach T, Zeeb C, Lawrenz B, Popovici $\mathrm{RM}$, et al. Ovarian stimulation to cryopreserve fertilized oocytes in cancer patients can be started in the luteal phase. Fertil Steril. 2009;92:1360-5. doi:10.1016/j.fertnstert.2008.08.011

44. Sonmezer M, Turkcuoglu I, Coskun U, Oktay K. Random-start controlled ovarian hyperstimulation for emergency fertility preservation in letrozole cycles. Fertil Steril. 2011;95:2125.e9-11. doi:10. 1016/j.fertnstert.2011.01.030

45. Cakmak H, Katz A, Cedars MI, Rosen MP. Effective method for emergency fertility preservation: random-start controlled ovarian stimulation. Fertil Steril. 2013;100:1673-80. doi:10.1016/j.fertnstert. 2013.07.1992

46. Marklund A, Eloranta S, Wikander I, Laczna Kitlinski M, Lood M, Nedstrand, et al. Efficacy and safety of controlled ovarian stimulation using $\mathrm{GnRH}$ antagonist protocols for emergency fertility preservation in young women with breast cancer - a prospective nationwide Swedish multicenter study. Hum Reprod 2020. doi:10. 1093/humrep/deaa029

47. Oktay K, Türkçüoğlu I, Rodriguez-Wallberg KA. GnRH agonist trigger for women with breast cancer undergoing fertility preservation by aromatase inhibitor/FSH stimulation. Reprod Biomed Online. 2010;20:783-8. doi:10.1016/j.rbmo.2010.03.004

48. Oktay K, Buyuk E, Libertella N, Akar M, Rosenwaks Z. Fertility preservation in breast cancer patients: a prospective controlled comparison of ovarian stimulation with tamoxifen and letrozole for embryo cryopreservation. JCO. 2005;23:4347-53. doi:10.1200/JCO. 2005.05.037
49. Azim AA, Costantini-Ferrando M, Oktay K. Safety of fertility preservation by ovarian stimulation with letrozole and gonadotropins in patients with breast cancer: a prospective controlled study. JCO. 2008;26:2630-5. doi:10.1200/JCO.2007.14.8700

50. Kim J, Turan V, Oktay K. Long-term safety of letrozole and gonadotropin stimulation for fertility preservation in women with breast cancer. J Clin Endocrinol Metab. 2016;101:1364-71. doi:10. 1210/jc.2015-3878

51. Moravek MB, Confino R, Smith KN, Kazer RR, Klock SC, Lawson AK, et al. Long-term outcomes in cancer patients who did or did not pursue fertility preservation. Fertil Steril. 2018;109:349-55. doi:10. 1016/j.fertnstert.2017.10.029

52. Rodgers RJ, Reid GD, Koch J, Deans R, Ledger WL, Friedlander M, et al. The safety and efficacy of controlled ovarian hyperstimulation for fertility preservation in women with early breast cancer: a systematic review. Hum Reprod. 2017;32:1033-45. doi:10.1093/ humrep/dex027

53. Rodriguez-Wallberg KA, Eloranta S, Krawiec K, Lissmats A, Bergh J, Liljegren A. Safety of fertility preservation in breast cancer patients in a register-based matched cohort study. Breast Cancer Res Treat. 2018;167:761-9. doi:10.1007/s10549-017-4555-3

54. Polland A, Berookhim BM. Fertility concerns in men with genitourinary malignancies: treatment dilemmas, fertility options, and medicolegal considerations. Urol Oncol. 2016;34:399-406. doi:10. 1016/j.urolonc.2016.05.007

55. Kelleher S, Wishart SM, Liu PY, Turner L, Di Pierro I, Conway AJ, et al. Long-term outcomes of elective human sperm cryostorage. Hum Reprod. 2001;16:2632-9. doi:10.1093/humrep/16.12.2632

56. Shankara-Narayana N, Di Pierro I, Fennell C, Ly LP, Bacha F, Vrga L, et al. Sperm cryopreservation prior to gonadotoxic treatment: experience of a single academic centre over 4 decades. Hum Reprod. 2019;34:795-803. doi:10.1093/humrep/dez026

57. Ferrari S, Paffoni A, Filippi F, Busnelli A, Vegetti W, Somigliana E. Sperm cryopreservation and reproductive outcome in male cancer patients: a systematic review. Reprod Biomed Online. 2016;33: 29-38. doi:10.1016/j.rbmo.2016.04.002

58. Druckenmiller S, Goldman KN, Labella PA, Fino ME, Bazzocchi A, Noyes N. Successful oocyte cryopreservation in reproductive-aged cancer survivors. Obstet Gynecol. 2016;127:474-80. doi:10.1097/ AOG.0000000000001248

59. Cobo A, García-Velasco JA, Coello A, Domingo J, Pellicer A, Remohí J. Oocyte vitrification as an efficient option for elective fertility preservation. Fertil Steril. 2016;105:755-64.e8. doi:10.1016/ j.fertnstert.2015.11.027

60. Cobo A, Garcia Velasco J, Domingo J, Pellicer A, Remohi J. Elective and onco-fertility preservation: factors related to IVF outcomes. Hum Reprod. 2018;33:2222-31. doi:10.1093/humrep/dey321

61. Donnez J, Dolmans MM, Demylle D, Jadoul P, Pirard C, Squifflet J, et al. Livebirth after orthotopic transplantation of cryopreserved ovarian tissue. Lancet. 2004;364:1405-10. doi:10.1016/S01406736(04)17222-X

62. Donnez J, Silber S, Andersen CY, Demeestere I, Piver P, Meirow D, et al. Children born after autotransplantation of cryopreserved ovarian tissue. A review of 13 live births. Ann Med. 2011;43: 437-50. doi:10.3109/07853890.2010.546807

63. Rodriguez-Wallberg KA, Karlström PO, Rezapour M, Castellanos E, Hreinsson J, Rasmussen C, et al. Full-term newborn after repeated ovarian tissue transplants in a patient treated for Ewing sarcoma by sterilizing pelvic irradiation and chemotherapy. Acta Obstet Gynecol Scand. 2015;94:324-8. doi:10.1111/aogs.12568

64. Hoekman EJ, Louwe LA, Rooijers M, Westerlaken LAJ, Klijn NF, Pilgram GSK, et al. Ovarian tissue cryopreservation: low usage rates and high live-birth rate after transplantation. Acta Obstet Gynecol Scand. 2020;99:213-21. doi:10.1111/aogs.13735

65. Andersen ST, Pors SE, Poulsen LC, Colmorn LB, Macklon KT, Ernst $\mathrm{E}$, et al. Ovarian stimulation and assisted reproductive technology outcomes in women transplanted with cryopreserved ovarian tissue: a systematic review. Fertil Steril. 2019;112:908-21. doi:10. 1016/j.fertnstert.2019.07.008 
66. Smitz J, Dolmans MM, Donnez J, Fortune JE, Hovatta O, Jewgenow $\mathrm{K}$, et al. Current achievements and future research directions in ovarian tissue culture, in vitro follicle development and transplantation: implications for fertility preservation. Hum Reprod Update. 2010;16:395-414. doi:10.1093/ humupd/dmp056

67. Telfer EE, Zelinski MB. Ovarian follicle culture: advances and challenges for human and nonhuman primates. Fertil Steril. 2013;99: 1523-33. doi:10.1016/j.fertnstert.2013.03.043

68. McLaughlin M, Albertini DF, Wallace WHB, Anderson RA, Telfer EE. Metaphase II oocytes from human unilaminar follicles grown in a multi-step culture system. Mol Hum Reprod. 2018;24:135-42. doi: 10.1093/molehr/gay002

69. Lee SJ, Schover LR, Partridge $A H$, Patrizio $P$, Wallace $W H$, Hagerty $\mathrm{K}$, et al. American Society of Clinical Oncology recommendations on fertility preservation in cancer patients. JCO. 2006;24: 2917-31. doi:10.1200/JCO.2006.06.5888

70. Goossens E, Van Saen D, Tournaye H. Spermatogonial stem cell preservation and transplantation: from research to clinic. Hum Reprod. 2013;28:897-907. doi:10.1093/humrep/det039

71. Oliver E, Stukenborg JB. Rebuilding the human testis in vitro. Andrology. 2019. doi: 10.1111/andr.12710 